\title{
Integration of GIS in the Development of an Environmental Cadastre Administrative System for the Environment Protection Agency Sierra Leone
}

\author{
Samuel Mohamed Kamara \\ Department of Geographic Information Systems, Environment Protection Agency, Freetown, Sierra Leone \\ Email: samuel.kamara@epa.gov.s1
}

How to cite this paper: Kamara, S.M. (2019) Integration of GIS in the Development of an Environmental Cadastre Administrative System for the Environment Protection Agency Sierra Leone. Journal of Geographic Information System, 11, 411-428. https://doi.org/10.4236/jgis.2019.114026

Received: March 27, 2019

Accepted: August 4, 2019

Published: August 7, 2019

Copyright () 2019 by author(s) and Scientific Research Publishing Inc. This work is licensed under the Creative Commons Attribution International License (CC BY 4.0).

http://creativecommons.org/licenses/by/4.0/ (c) (i) Open Access

\begin{abstract}
The Environment Protection Agency Sierra Leone (EPA) is mandated by law to issue Environmental Impact Assessment license. Currently the agency achieves this mandate by issuing environmental licenses manually which always encountered lot of problems of accountability and transparency of the management of environmental licenses and assessment documentation. Client's information and documentation is usually mixed up while carrying files from one point to the other or from one staff to another. Data on client are stored in a way which makes it difficult for the management to retrieve useful information on time. This paper explores these challenges faced by the manual system of issuing environmental licenses and infer solutions to the current challenges by integrating a Geographic Information Systems (GIS) to develop an Environmental Cadastre administrative System (ECAS) which establishes a web-based information repository database developed with open sources software (Java, PHP, MySQL, QGIS) that published revenues online and made the data available to stakeholders and/or the public to complete the cycle of accountability and transparency. The information is presented and downloadable in a comprehensible and user-friendly manner, which in turn improves monitoring and reporting, and increases effectiveness and accountability of the management of environmental licenses and assessment documentation. The findings show these challenges facing the manual system, the back and forth between EPA and the client in the EIA process, the difficulty in the searching a client record, the mixing up of Client's information and documentation by carrying files from one point to the other, and the storage of data on client in a way which makes it difficult for the management to retrieve useful information on time, and lack of back up when data or informa-
\end{abstract}


tion is lost. Problems encountered in the time-consuming nature of the manual retrieval of files and preparation of prompt and accurate reports make it become a difficult task to accomplish as data and information are difficult to retrieve or collect from various files. Based on these findings, this paper provides the possible solution to the above problems. An online Environmental Cadastre administrative System (ECAS) which establishes a web-based information repository database was designed to capture the full lifecycle of environmental licenses including all stages of monitoring, licenses and payments and seamlessly manage the environmental impact assessment (EIA) licenses.

\section{Keywords}

Environmental Cadastre Administrative System, Environmental License, GIS, Environmental Impact Assessment, Environment Protection Agency

\section{Introduction}

The EPA Act which was signed as a legal document in September 2008 and amended in July 2010 and the Agency was established [1] [2]. Following the enactment of this Act, an Environmental Impact Assessment Report (EIA) is demanded for certain types of project activities [1]. A potential project, requested to carry out EIA studies, would be mandated to commence its operations, by the issue of an EIA license, on approval of the submitted EIA report [1]. Currently the agency achieves this mandate by issuing environmental licenses manually which always encountered a lot of problems of accountability and transparency of the management of environmental licenses and assessment documentation. Client's information and documentation is usually mixed up while carrying files from one point to the other or from one staff to another. Data on client are stored in a way which makes it difficult for the management to retrieve useful information on time.

This paper explores these challenges faced by the manual system of issuing environmental licenses and infers solutions to the current challenges by integrating a Geographic Information Systems (GIS) to develop an Environmental Cadastre administrative System (ECAS) which establishes a web-based information repository database developed with open sources software (Java, PHP, MySQL, QGIS) that published revenues online and made the data available to stakeholders and/or the public to complete the cycle of accountability and transparency. Geographic Information Systems (GIS) has the capability to improve the gathering, storage manipulation, transformation and processing of data and information. GIS contribution in environmental impact assessment studies is very important and very useful for managing environmental impact assessment licenses and data consistently from field measurement.

The ECAS is a web-based system which allows the agency to seamlessly man- 
age the environmental impact assessment (EIA) licenses. The information is presented and downloadable in a comprehensible and user-friendly manner, which in turn improves monitoring and reporting, and increases effectiveness and accountability of the management of environmental licenses and assessment documentation.

It provides standardized online storage, retrieval and updating facility that enables the use of very less paper work. Information can be retrieved very easily without searching here and there into files. The ECAS is a modern tool necessary to manage licenses within the environmental sector. The system enables the Environment Protection Agency Sierra Leone to possess and efficiently utilize a more effective administrative system to manage the full life cycle of environmental licenses and revenues from fees and payments. This provides the public with a better status of the environmental impact assessment licenses.

The ECAS increase the effectiveness and accountability of the management of environmental licenses and assessment documentation in a systematic process, for all environmental operations. This systematic process improves the government's ability to absorb revenues, increases government's auditing capabilities, and boosts investor confidence in the state's authority. Based on the EIA license lifecycle (Figure 1), ECAS captures the full lifecycle of environmental licenses including all stages of the Environment Impact Assessment Studies.

\section{Statement of the Problem}

The insurance of an EIA license faces a lot of problems which is manual and depends on paper to collect all reports. So, it needed to introduce an information technology based administration system solution, built on the existing laws and regulations. This system makes the data available to stakeholders and/or the public which will reduce the license processing time. Some of the problems faced by the current system are stated below:
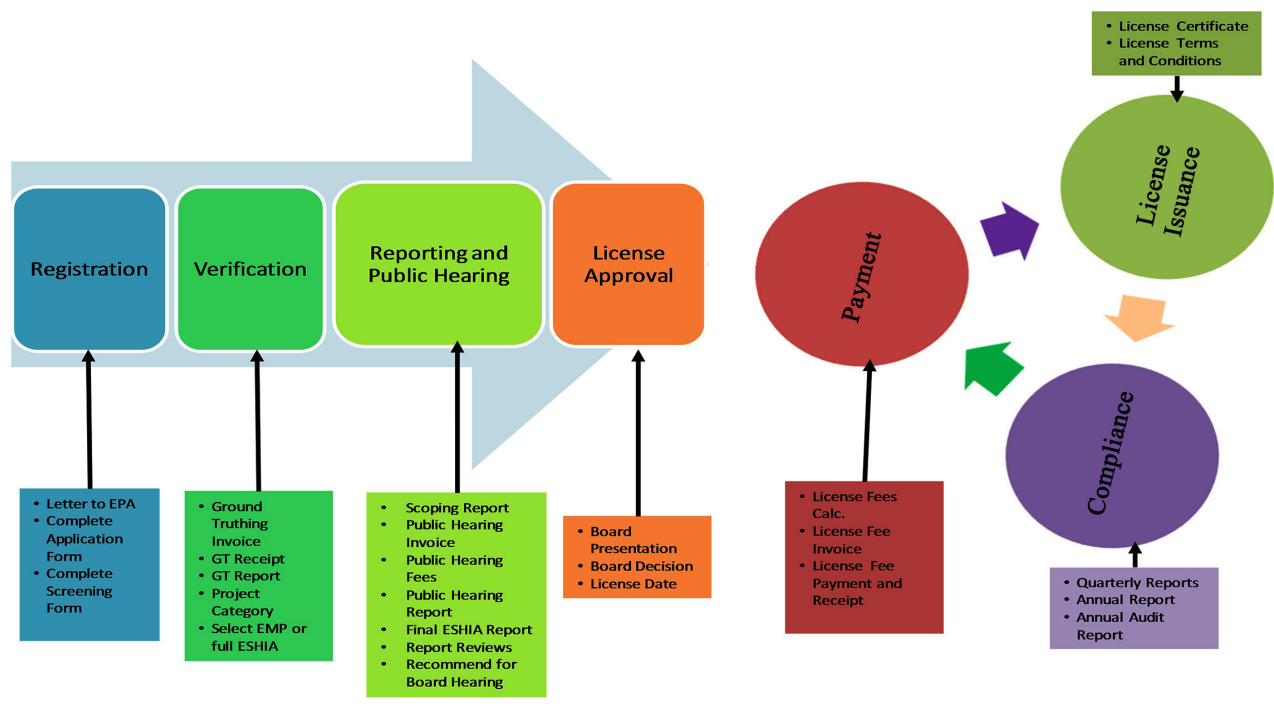

Figure 1. Main phase of an EIA license process. 
1) The EIA license process is document heavy and for anyone to review a client's files they must look at the physical files in administration.

2) Client's information is usually mixed up while carrying files from one point to the other or from one staff to another.

3) Data on client is stored in a way which makes it difficult for the management to retrieve useful information on time.

4) The agency does not have back-up of data and documents records in the case of natural disaster for example fire outbreak.

5) Missing of most of the client's records.

6) Problems were encountered in the time-consuming nature of the manual retrieval of files for various reasons from the existing records system.

7) All license processes are issued manually.

This paper explores these challenges faced by the manual system and infers solutions to those challenges.

\section{System Aim and Objectives}

Aim: To Integrate GIS in the development of an Environmental Cadastre Administrative System (ECAS) that provides effectiveness and accountability of the management of environmental impact assessment licenses and assessment documentation. The objectives of this study are:

1) To develop a database system that allows all stages of the EIA licenses process to be managed;

2) To integrate GIS to develop a web base Environmental Cadastre Administrative System (ECAS) for the effective management of the environmental impact assessment license life cycle.

The proposed system provides an administrative system that handles any type of environmental impact assessment license data and information. It captures the full lifecycle of environmental licenses including all stages of monitoring, licenses and payments and assists EIA companies to prepare completes and efficient ESHIA report in a very short time.

\section{Research Methodology}

The research methodology is based on Process review, field work and technical assessment. Assessment of the existing system is done, user requirement studies were also done to ascertained the gaps in the existing system and provides solutions in the new system. The results were used to design the ECAS and the outputs were produced.

\section{Problem of the Existing System}

The process review revealed several challenges facing the current manual system for EIA Licenses. These are listed below;

1) The Current EIA License process has a lot of back and forth between EPA and the client. 
2) The EIA license process is document heavy and for anyone to review a client's files they must look at the physical files in administration.

3) There have been cases where clients have licenses but it is difficult to ascertain whether the proper documentation was submitted.

4) The compliance department has a hard time ascertaining which companies have expired licenses and which ones have not yet submitted required reports.

5) Currently EIA licenses and reports are tracked through an excel template which is sometimes not well updated.

6) Lack of EIAs document and information storage, the documents generated by various EIA reports take time and effort to be stored at right places.

7) Issuance of EIA license on time, this becomes a difficult task as information is difficult to collect from various files and registers.

\section{Development of the Environmental Cadastre Administrative System (ECAS)}

The ECAS is a GIS-based decision support system that is developed to comprehensively captures the full life cycle of environmental impact assess license including all stages of monitoring, license and payments and seamlessly manage the environmental impact assessment license. The process of integrating GIS spatial database was accomplished by using relational database concept. The main softwares used in this study are Java, PHP, MySQL, QGIS which are open source software. The purpose of the system is to Integrate GIS in the development of an Environmental Cadastre Administrative System (ECAS) that provides effectiveness and accountability of the management of environmental impact assessment licenses and assessment documentation.EPA will implement the Environmental Cadastre Administration System (ECAS) to assist in the processing of licenses. The ECAS is seen as a modern tool necessary to manage licenses and permit within the environmental sector. The system enables the Environment Protection Agency Sierra Leone to possess and efficiently utilize a more effective administrative system to manage the full life cycle of environmental licenses and revenues from fees and payments. This provides the public with a better status of the environmental impact assessment licenses. ECAS is designed to follow the typical life-cycle of an EIA license.

As represented in Figure 2, The ECAS is developed using the following steps; Technical assessment and Review of the existing system, defining components of the ECAS, development of system component database, system database integration. Each step will be explained in detail in the subsequent sections.

\subsection{ECAS System Assumptions}

For the insurance of EIA license the ECAS is based on two assumptions, the first is that all EIA studies, component and prescribe activities were classified, the system assumes that all these categories are sector specific and EIA license fees are calculated based on these sectors, the second assumption is all documents, 
reports, and processes that lead to the insurance of EIA license are uploaded into the web based system. The ECAS captures the full lifecycle of environmental licenses including all stages of monitoring, licenses and payments which involves nine modules. Figure 3 shows all these assumptions and the system predevelopment preparations. The system collates various types of data in regards to licenses and allocation of land for various projects which gives a comprehensive picture of the environmental footprint of various projects across the country at a glance.

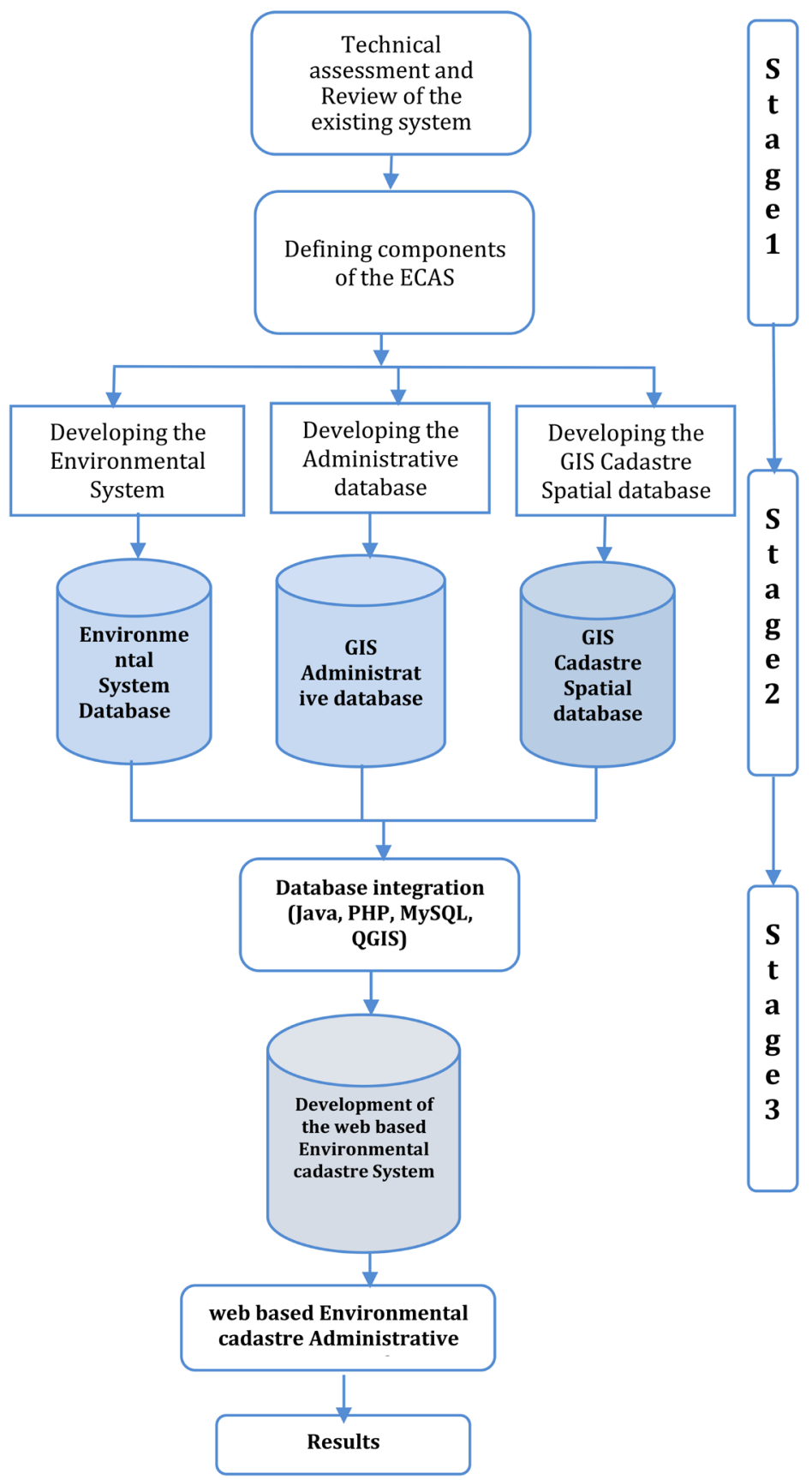

Figure 2. ECAS development work flow. 


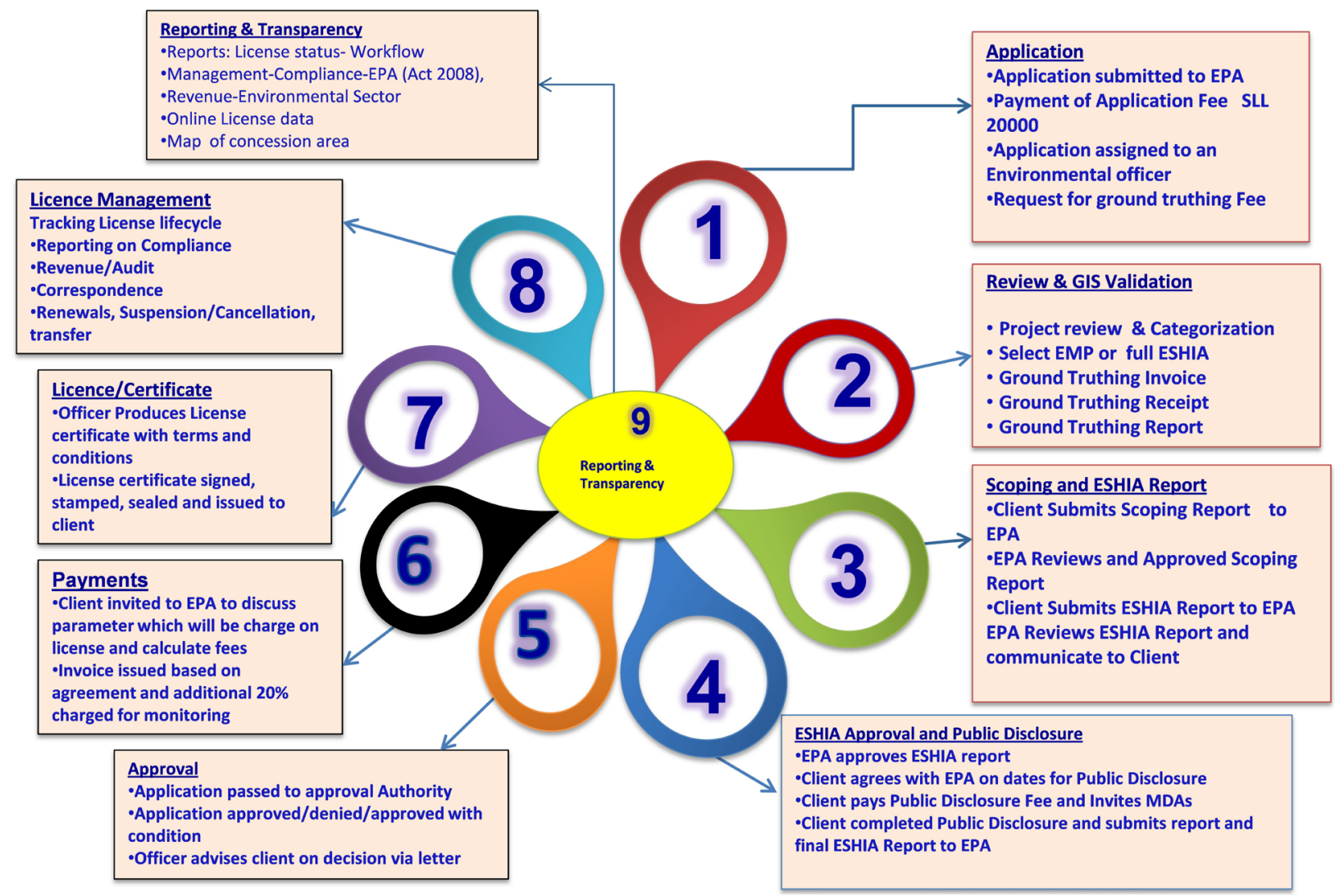

Figure 3. Environmental cadastre administrative system predevelopment preparation.

\subsection{Component of the Environmental Cadastre Administrative System (ECAS)}

The ECAS mainly consists of an Environmental database management system, a GIS Cadastre Spatial database management system, an Administrative database management system and a web based Administrative database management system that captures the entire life cycle of the EIA license system. Detailed of these systems are explained in the subsequent sections.

1) Environmental database management system: The function of the Environmental database management system is to manage all environmental information and data of the EIA license lifecycle. The system assumes that all EIA studies, component and prescribe activities were prepared which include application letters, screening and application form, business registration certificates, receipt of payment of application fee, business plan. The system is subdivided into two stages namely the system development stage, Figure 4 , here the system functions to process, store and manage all application information and data about all EIA license applications, secondly the system operations stage (Figure 5 ), here the system provides different functions to the users by using the environmental database management system.

The main function is to prepare EIA license reports through several steps.

The system allows the user to store, information about the EIA license process and allowed the user to perform the following [3]. 


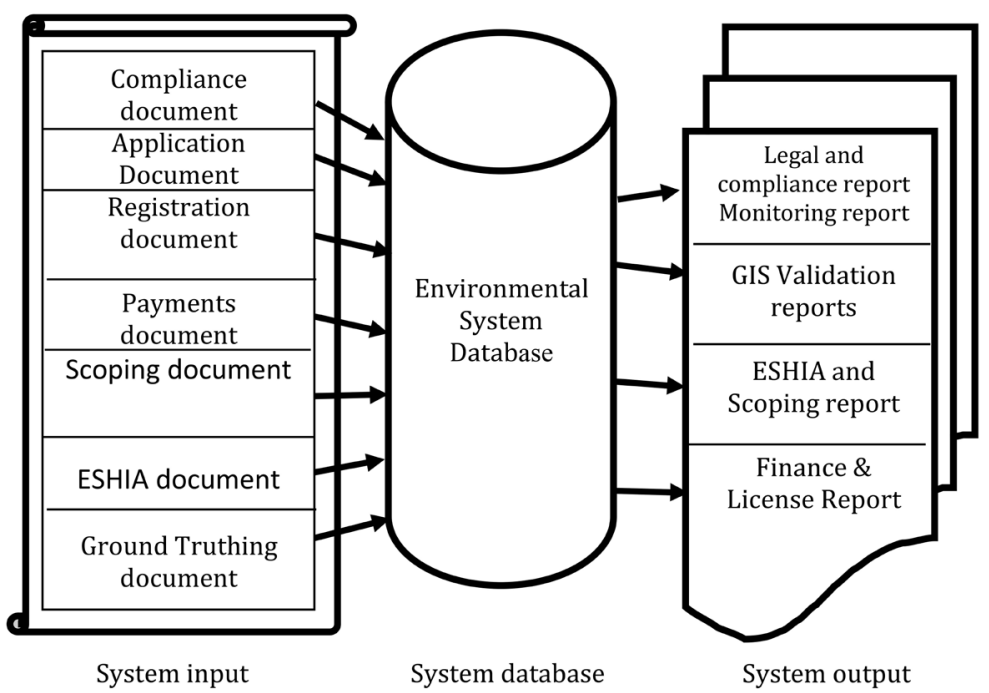

Figure 4. System development stage.

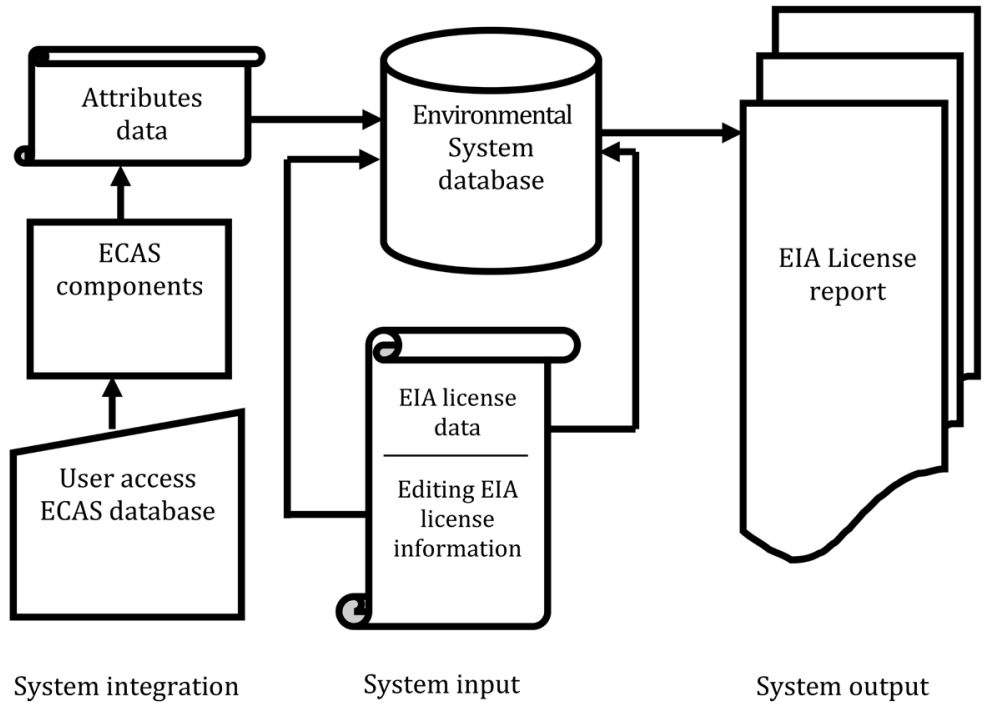

Figure 5. System operating stage structure.

a) Registration: The user registers the project in the system, and uploads the screening form and receipt of payment, this is done through data entering forms and screens using the ECAS web base interface which provide facilities to add, edit, delete, retrieve, review, upload and save data and information items.

b) Screening and Ground Truthing: The EPA screens the forms in the system to determine whether an EIA is required, and the level of detail required and Ground Truthing exercise conducted. Once the Ground Truthing exercise is completed the GIS officer enters the coordinates into the system and performs validation to check the GIS Coordinates as issued by the client. The system has capability to prepare report and analysis to describe the status of the license process.

c) Scoping: The applicant submits a scoping report that sets out the scope of 
the EIA, the issues to be addressed and the draft Terms of Reference. Scoping report reviewed by the environmental officer, and uploaded into the web based system and pushed for approval by the Executive Chair of EPA.

d) ESHIA Studies: Once the scoping report is approved the applicant notifies and engages with stakeholders and then makes the impact studies.

e) Review of ESHIA Report: Applicant submit study and user upload and review final approved report then Applicant pays Public Disclosure Fees. An invoice is issued by Finance Department through the system and usually the fee is paid to a specified bank account and then a receipt issued by the Finance Department of EPA through the system.

2) GIS Cadastre Spatial database management system: The system collates various types of data in regards to licenses and allocation of land for various projects which gives a comprehensive picture of the environmental footprint of various projects across the country at a glance. Figure 6 shows the establishment of the GIS Cadastre Spatial database management.

The establishment of the database includes a series of process such as attributes data inputting, data selecting, data inputting. The system is related to various data types and format. In detail, the inputted data are categorized by extensively data sources: including remote sensing images, scanned image data, data in Excel and other text format. The spatial database is stored as points, polylines, and polygons. The information of the decision making level is determined when entering data into the system, the system with GIS integration, able to detect anomalies such as land overlaps, missing information or documents and notify when any reports are due or are coming up for review.

3) The Administrative database system: The function of the administrative database management system is to manage all environmental licenses issued through the system. Its main function is the management of the decision making and license approval and issuance process through the following steps.

\section{a) Decision Making: Approval and License Issuance}

Once the environment officer is satisfied with the ESHIA report with the guidance of the rules and regulations set by the Agency Act, the application presented to the EPA Board for decision making and progress to the approval and issuance phase (Figure 7). The ESHIA Report is either approved or rejected by the EPA's Board, and an EIA License granted/not granted. It is subject to terms, conditions and renewal. The board can arrive at one of three decisions [4]:

i) Approved-Client can go ahead and implement the project.

ii) Denied-Client should not proceed with the project.

iii) Approved with conditions-Client must fulfill certain conditions before license is issued but does not have to seek another Board approval. The license becomes active on the day that the Board provides approval.

b) Compliance and Enforcement: Environmental monitoring and auditing of the project activities are undertaken to ensure that the terms and conditions of the EIA License are met. The system tract all the monitoring and auditing of all stages in the EIA license process. 


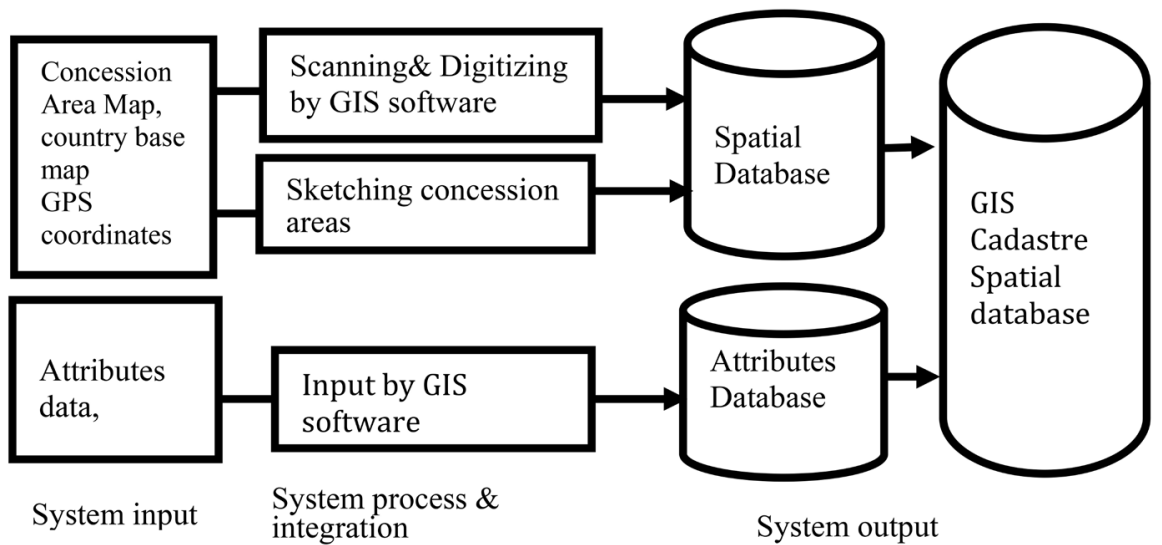

Figure 6. Establishment of the GIS cadastre spatial database.

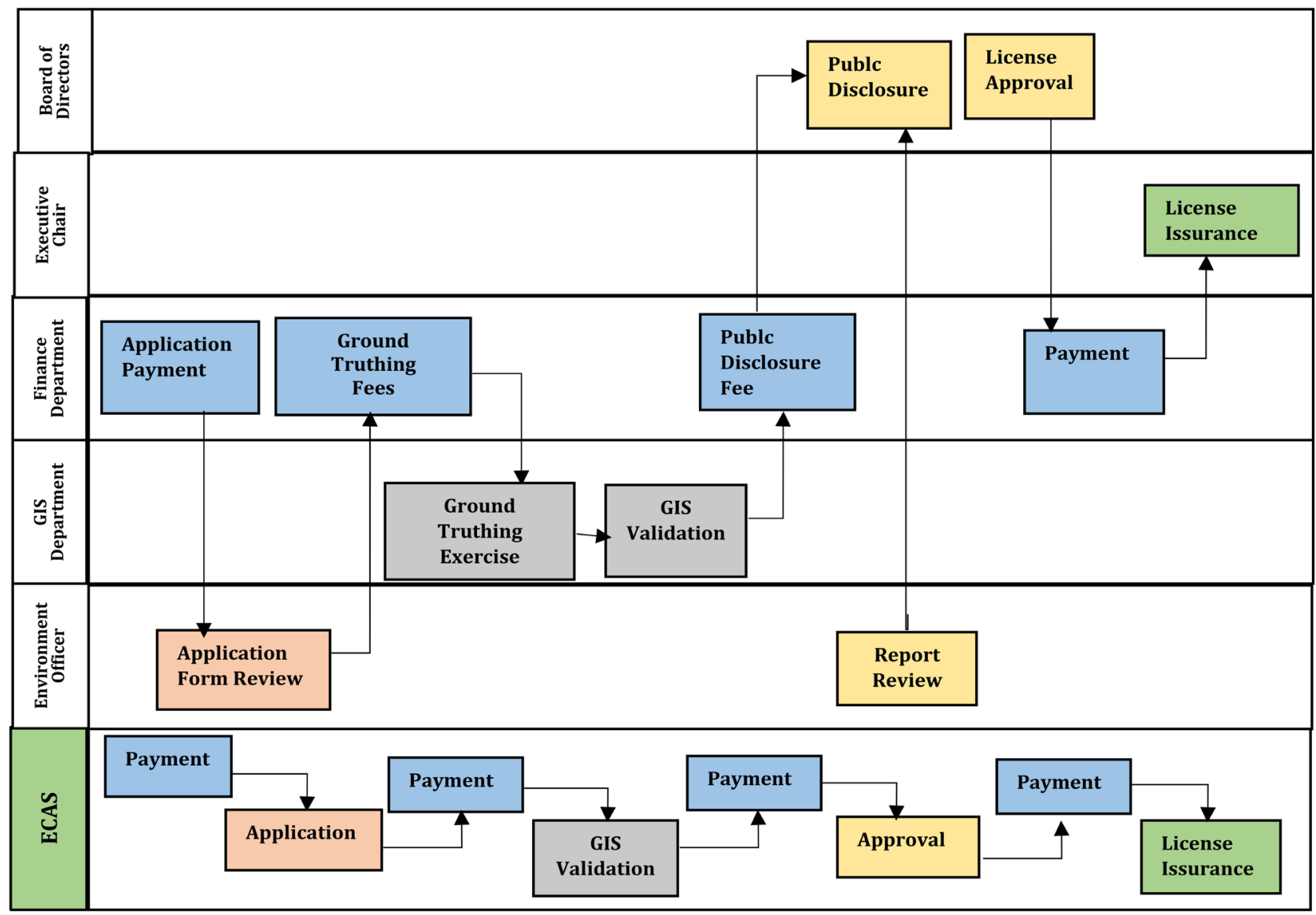

Figure 7. Environmental impact assessment license decision making, approval and license issuance work flow.

Figure 7 shows the Environmental Impact Assessment License Decision making, Approval and License issuance work flow. The ECAS captures the full lifecycle of environmental licenses including all stages of monitoring, licenses and payments. ECAS record payments associated with licenses, and ensure that public administrators determine what fees need to be paid, when, and why, as well as what administrative procedures are needed to maintain the legal status 
and compliance of the license [5]. ECAS seamlessly generate required correspondence and prompt the suspension of non-compliant licenses. This entire process is reflected in the system dashboard which forms an intuitive operations planning tool for public administrators with which they can manage staff workload and productivity. The Reports and Analysis Module of ECAS provides configurable reporting templates where users and stakeholders can run pre-formed or customized reports to view or export as MS Excel data or PDF reports. These reports provide a holistic understanding of the licensing process as well as full details on the companies, their locations and what type of projects they are seeking licenses for. The reports also show payments which have been processed for each license and for what reason thus giving a clear view of the payments in the licensing process.

ECAS is configured so that a user must strictly adhere to processes and cannot proceed with the issuance of a license if the correct fees, documents and approvals have not been provided. Therefore, the documentation of the licenses issuance processes is a critical step towards compliance.

4) The Web based cadastre database management system: The Web based cadastre database management system was developed based on the established Environmental database management system, the GIS Cadastre Spatial database management system, and the Administrative database management system. Combining all these database systems give the full life cycle of the ECAS (Figure 8). The web base Environmental Cadastre Administrative System (ECAS) is built using open sources software (Java, PHP, MySQL, QGIS). The ECAS allows the agency to seamlessly manage the environmental impact assessment (EIA) licenses. It provides a standardized online storage, retrieval and updating facility that enables the use of very less paper work and rendered help to the agency staff. All documents and data are stored electronically that enables less use of paper and information can be retrieved very easily without searching here and there into files. It provides a standardized online storage, retrieval and updating facility that enables the use of very less paper work and also rendered help for the agency staff. All documents and data are stored electronically that enables less use of paper and information can be retrieved very easily without searching here and there into files. The ECAS is seen as a modern tool necessary to manage licenses and permit within the environmental sector. The system enables the Environment Protection Agency Sierra Leone to possess and efficiently utilize a more effective administrative system to manage the full life cycle of environmental licenses and revenues from fees and payments. This provides the public with a better status of the environmental impact assessment licenses. ECAS is designed to follow the typical life-cycle of an EIA license. ECAS will manage the licensing lifecycle from application to renewal and license management. Once the system is populated with information, EPA will be able to process various reports and if they so wish to publish the license data on the Government of Sierra Leone (GoSL) online repository. 


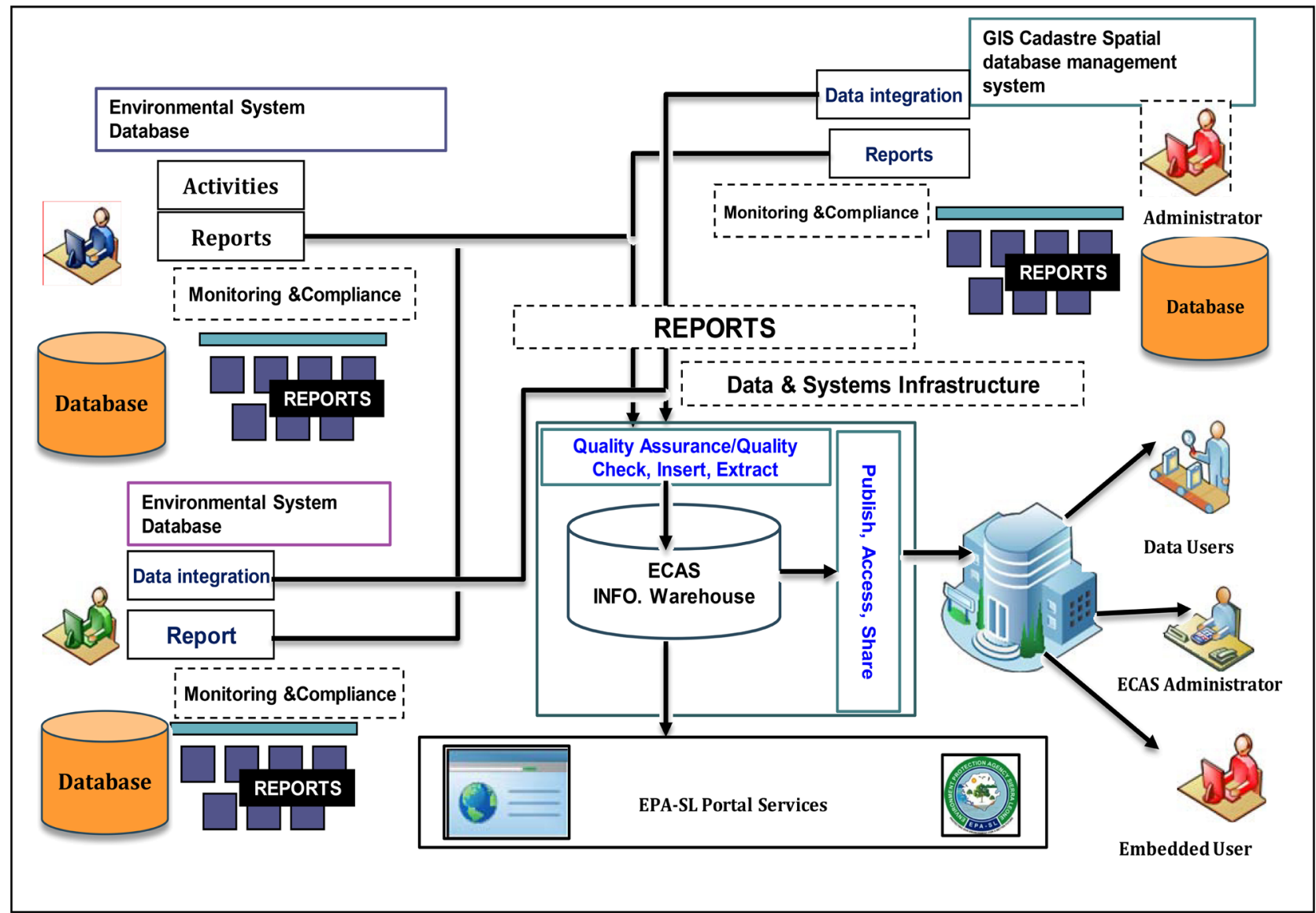

Figure 8. Establishment of the web based Environmental Cadastre Administrative System (ECAS).

\subsection{Possible Solutions to the EIA Manual License Process}

An alternative solution to the manual system is the improvement of the manual system which provides solutions to the following;

1) The back and forth process of the Current EIA License process can be reduced by setting up ECAS licenses operation office that accepts and processes all License Documentation.

2) Having qualified officers review EIA documents before accepting them to minimize the need to contact the client for additional information i.e. reject any incomplete reports before they are submitted;

3) The ECAS system will make the process of reviewing files easier by allowing scanning and uploading of documents and creating centrally accessible files for each client's documents. The scanning and uploading of documents will also create a reliable archive and minimize the loss/damage of documentation;

4) The ECAS system has the functionality to ensure the person inputting information uploads all required documents before proceeding to the next stage;

5) ECAS will resolve the problem of ascertaining which companies have expired licenses and which ones have not yet submitted required reports by giving a summary of reports which are about to be due also flagging any companies which have expired licenses or have overdue reports. 


\section{Results}

The ECAS was developed in order to manage and comprehensively captures the full life cycle of environmental impact assessment license including all stages of monitoring, license and payments. Integrating GIS in the development of (ECAS) provides effectiveness and accountability of the management of environmental impact assessment licenses and assessment documentation. ECAS manage the licensing lifecycle from application to renewal and license management.

Figure 9 shows the staff login page with username and password, while Figure 10 shows the default start site call Task Module "My Tasks" it provides an overview of what actions need to be taken for specific application, active licenses, payments or reports, categorized by record types. My Task Module is user setting dependent, meaning that if the logged in user is only allowed to process validation, and only pending validation tasks will appear in the Task Module. One can filter between Applications, Active License, Payments and Reports and click the required Status or License Type to view specified list of records. The illustration in Figure 11 and Figure 12, shows how the Environment officer registered the new applicant and push the applicant to the various stages ranging from registration, Validation, Approval, License pending, which is document and compliance driven. The review and GIS module shown in Figure 13, enables the user to enter the GPS coordinates for the required application concession area, the area is automatically mapped and the total area calculate and linked to the applicant documents in the database with a unique application code then the required application validated under the Validation section. After the land has been validated, the license is generally sent for approval. At the approval stage, the environmental officers and Finance officers will prepare the application for formal Board approval by completing the following steps.

Uploading Scoping Report: Once the client submits the scoping report then this will be uploaded into the system.

Payment of Public Disclosure Fees: Using the "Add Fee" feature on the Application details page, the Finance Officer will process the payment of Public Disclosure Fees to allow for the Disclosure sessions to take place.

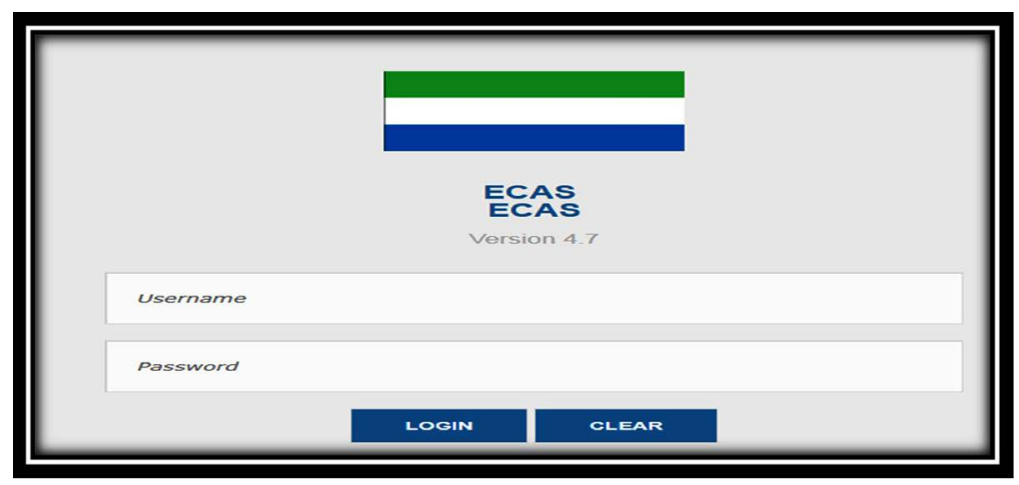

Figure 9. ECAS login module. 


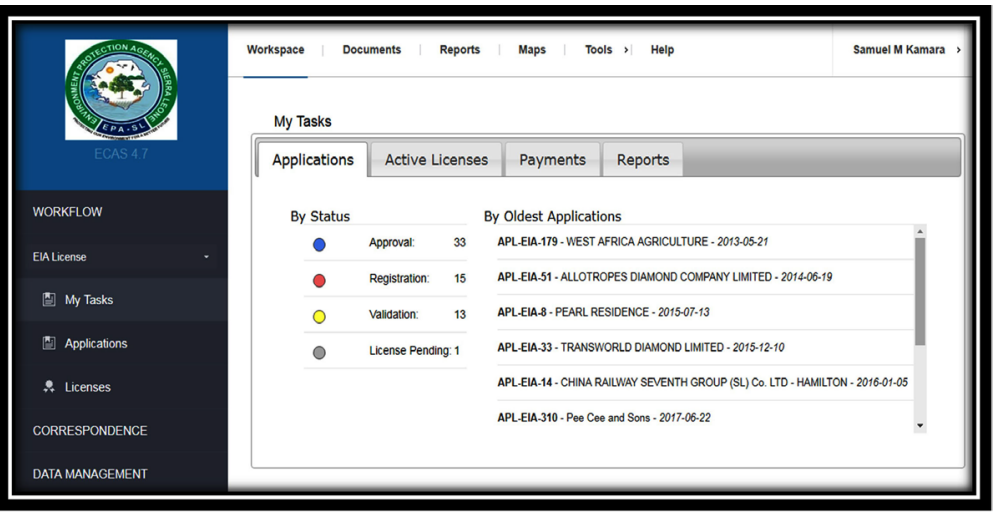

Figure 10. ECAS default task module.

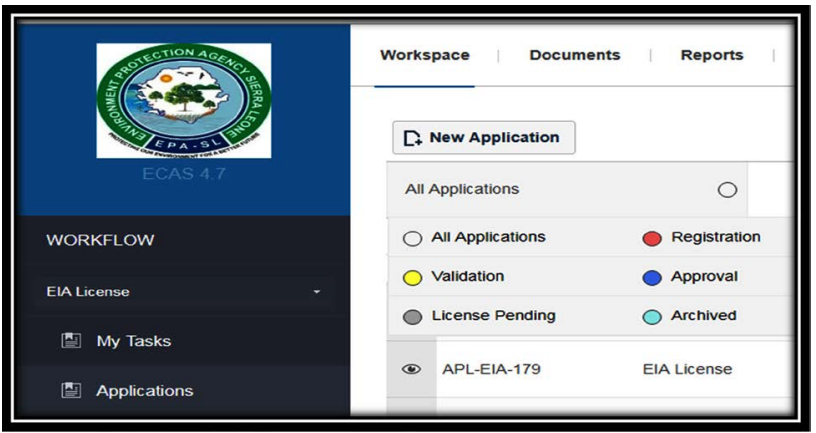

Figure 11. ECAS application module.

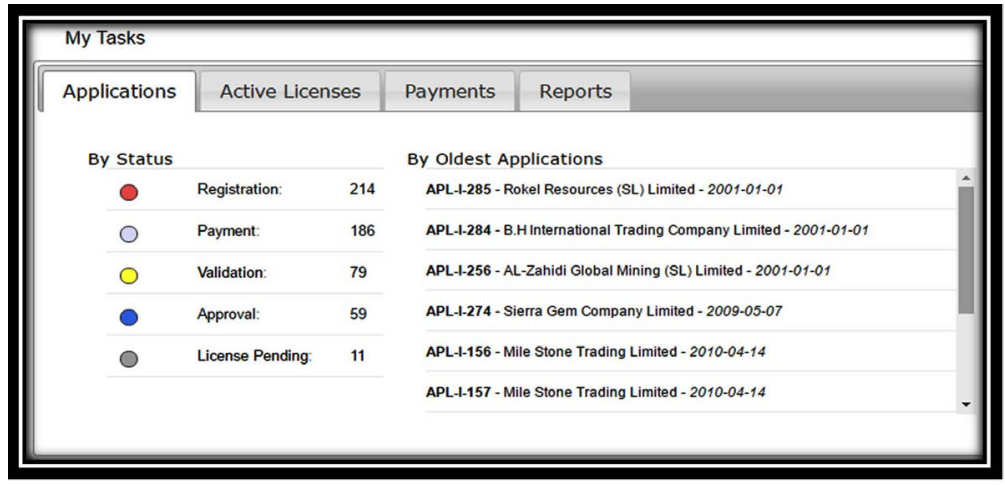

Figure 12. Status in the application process.

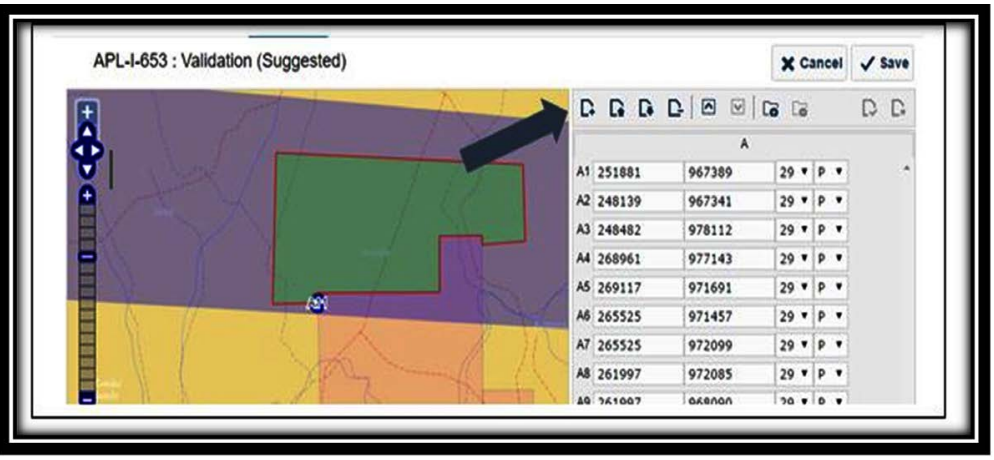

Figure 13. GIS module. 
Uploading of Final Reports: Using the add documents feature; the Environment Officer will upload Public Disclosure Report and the Final ESHIA report. Once all these reports are loaded the application will be ready to be reviewed by the Board for approval. Once The Board provides approval, the approving officer then completes the following steps:

1) The Environment Officer can now find the application under the Approval section.

2) Once a decision has been made, Environment Officer should type that into the system.

3) Environmental Officer does that by first entering the concerned record.

4) If the application has been denied the Environment Officer need to enter a note on reason, using the Add Note button.

5) If the application has been approved the Environment Officer need to add the approval document. After adding either relevant note or document Environmental Officer need to confirm the denial or approval, using the appropriate action buttons (Approve/Deny).

6) If approving the concerned record will move to the License Pending Stage, if denied it will go to Registration.

Having processed the application correctly and successfully through the above-described stages the system will now place the application in the License Pending section. Further, when clicking the Active Licenses Tab, one will be able to click and see a specified list of licenses by status, date of expiration (There are 214 active licenses, 59 in approval and 11 in License Pending. By date (Figure 12), from the image in Figure 13, we have 0 licenses expiring this week, 0 in 30 days and 0 in 60 days). Figure 14 shows the payment module. When you click on the Payment Tab, one will be able to find fees/Order to Pay (OTP) created by notification date, due date, expiring date and past expiring. Also one will be able to monitor OTP over due by days (7, 30 and 60 days). Further, when one clicks on the Reports Tab, one will be able to access different reports submitted by license Holders. The report tab categorizes reports under; Overdue Reports-reports due yet not submitted, Report with Issues-reports submitted but having issues with compliance and Received but not Reviewed reports to be reviewed (Figure 15). The User can also filter the data according to Licenses or Applications. The first thing the user sees when $\log$ in is the workspace interface containing a list of all licenses. In the left sided menu, you can change whether you want to view licenses or applications and whether you wish to view EIA License, Permits/applications. Clicking applications will also allow you to add and process a new application. You navigate within these records using the search tools above the list of licenses. These search tools will allow you to locate a specific license(s) by typing either owner's name, license or application code. Once you start entering details the system will automatically generate a list with fewer entries until you find the record you are looking for. Finally, you can search and categorize the records by status. To do this, simply click on Active, Suspended, etc. The options will appear when hovering the mouse over All Licenses (Figure 16). 


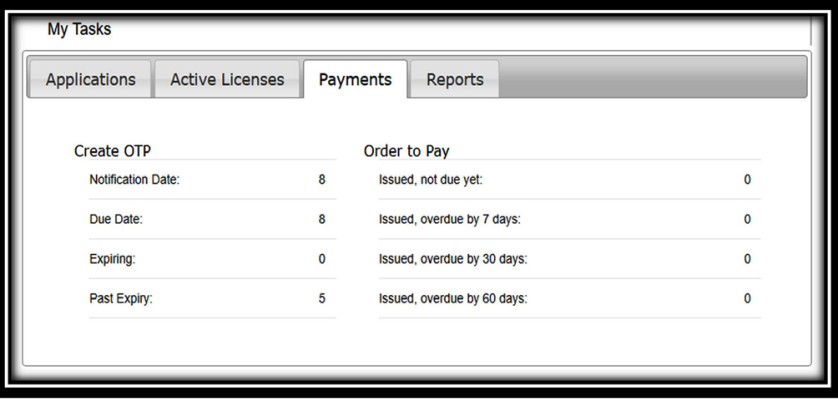

Figure 14. Payment module.

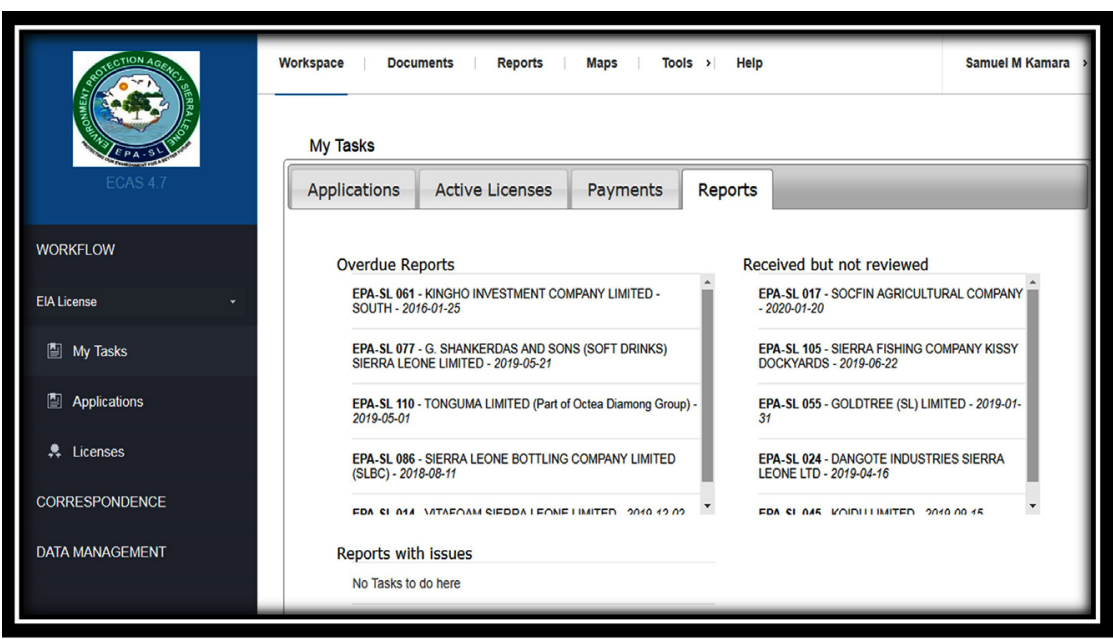

Figure 15. Report module.

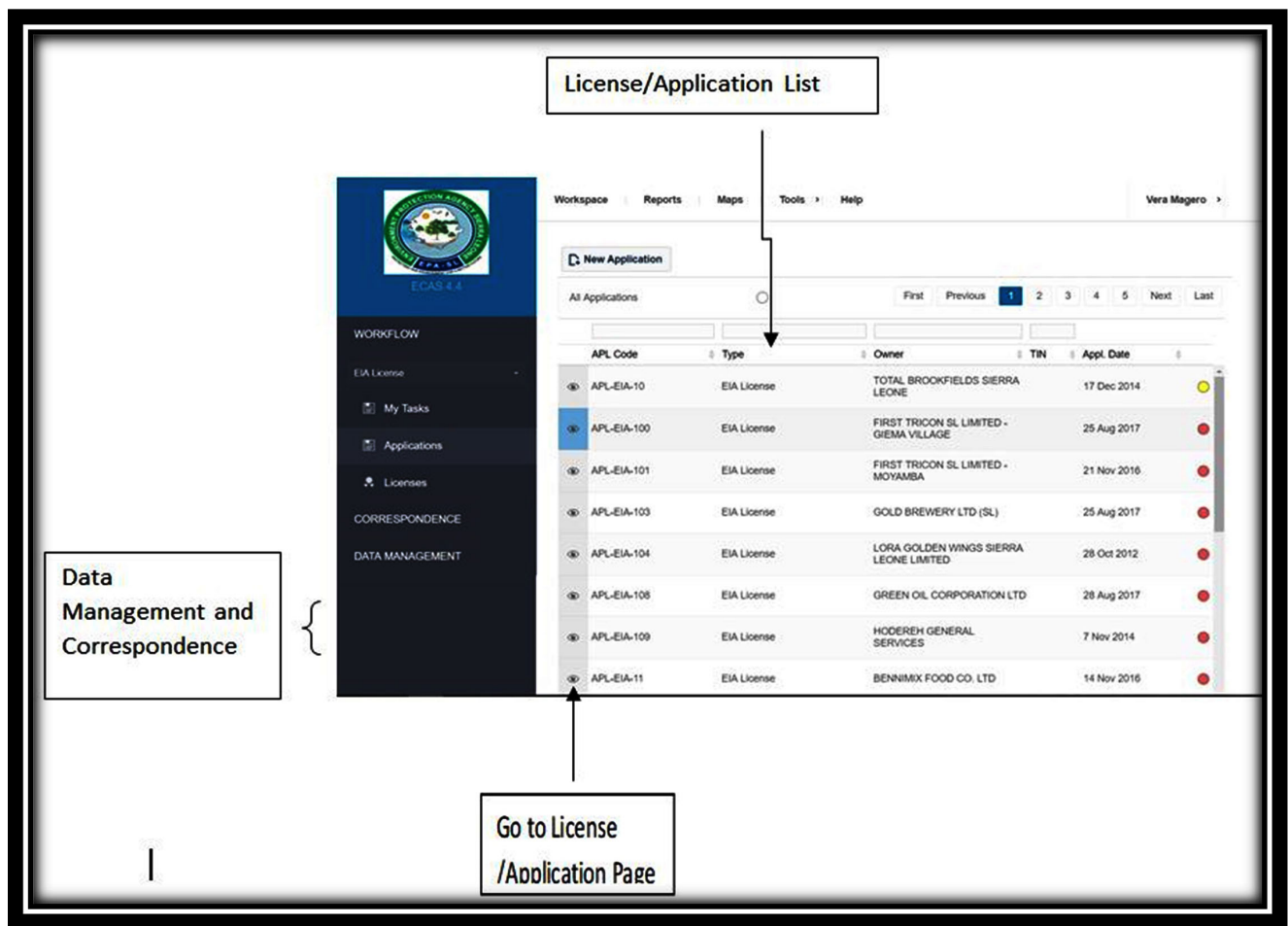

Figure 16. The workspace interface. 


\section{Advantages of the New System}

1) The Environmental Cadastre Administration System (ECAS) enable EPA to process EIA licenses in an organized and systematic manner.

2) The system also collates various types of data in regards to licenses and allocation of land for various projects which gives a comprehensive picture of the environmental footprint of various projects across the country at a glance.

3) ECAS enable EPA to have license information that is readily available and accurate. When entering data into the system, the system will be able to detect anomalies such as land overlaps, missing information or documents and notify when any reports are due or are coming up for review.

4) ECAS captures the full lifecycle of environmental licenses including all stages of monitoring, licenses and payments.

5) ECAS record payments associated with licenses, and ensure that public administrators can determine what fees need to be paid, when, and why, as well as what administrative procedures are needed to maintain the legal status and compliance of the license.

6) ECAS seamlessly generate required correspondence and prompt the suspension of non-compliant licenses. This entire process is reflected in the system dashboard which forms an intuitive operations planning tool for public administrators with which they can manage staff workload and productivity.

7) The Reports and Analysis Module of ECAS provides configurable reporting templates where users and stakeholders can run pre-formed or customized reports to view or export as MS Excel data or PDF reports. These reports provide a holistic understanding of the licensing process as well as full details on the companies, their locations and what type of projects they are seeking licenses for. The reports also show payments which have been processed for each license and for what reason thus giving a clear view of the payments in the licensing process.

\section{Conclusion and Recommendation}

In conclusion, the ECAS captures the full lifecycle of environmental licenses including all stages of monitoring, licenses and payments and its saves time and money for the agency. It improves the operations of the EIA license process, records management, data integration, GIS integration and validation, and data analysis and gives the power to access, analyses, process and manipulate EIA information quickly and efficiently. The problems faced in the manual system, unavailability of backup, delayed in finding documents and files; the delay in reviewing reports and corresponding to applicants have been minimized. The ECAS system ensures information and data authenticity, accuracy, and availability at any time and in a fast and efficient manner. The ECAS spatial database management system is therefore a great advantage to the Environment Protection Agency Sierra Leone. This web base administrative system database is now recommended for management of all EIA license process and the Agency administrative documentation. 


\section{Conflicts of Interest}

The author declares no conflicts of interest regarding the publication of this paper.

\section{References}

[1] The Sierra Leone (2008) Environment Protect Agency Act.

[2] The Sierra Leone (2010) Environment Protect Agency amended Act.

[3] The Sierra Leone (2010) Environment Impact Assessment License Regulations.

[4] The Sierra Leone (2010) Environment Protect Agency EIA Checklist.

[5] The Sierra Leone (2009) Mines and Minerals Act. 